\title{
Exercise therapy for osteoporosis: results of a randomised controlled trial
}

The University of Vienna, Vienna, Austria:

Department of Physical Medicine and Rehabilitation

E Preisinger, lecturer

Y Alacamlioglu, research assistant

K Pils, research assistant E Bosina, research assistant

\section{First Department of Obstetrics and Gynaecology M Metka, research assistant}

\section{Institute of Medical}

Statistics

B Schneider, research assistant

Postgraduate Medical School, University of Exeter, Barrack Road, Exeter EX2 5DW, United Kingdom E Ernst, professor

Correspondence to: Prof Edzard Ernst.

Accepted for publication 27 November

Elisabeth Preisinger, Yesim Alacamlioglu, Katharina Pils, Elizabeth Bosina, Markus Metka, Barbara Schneider, Edzard Ernst

\begin{abstract}
Objective-To define the effects of therapeutic exercise on bone density and back complaints.

Methods-A randomised controlled trial with parállel groups was conducted in an outpatient clinic, Medical School, University of Vienna. Ninety two sedentary postmenopausal women with back problems were randomly allocated to either exercise (groups 1 and 2) or control (group 3, no exercise, $n=31$ ); the exercise group was retrospectively subdivided into compliant (group 1, $n=27$ ) and not fully compliant patients (group 2, n=34). Regular, initially supervised therapeutic exercise aimed at restoring biomechanical function was performed for four years. Bone density in the forearm was measured by single photon absorptiometry at entry and after four years; subjective back complaints were documented.
\end{abstract}

Results-A significant decrease in bone density was observed in groups 2 and 3; no change was noted in group 1; back complaints decreased in group 1 only.

Conclusions-Sedentary postmenopausal women may benefit from regular long term therapeutic exercise in terms of subjective back complaints and slowed loss of bone mass.

(Br f Sports Med 1996;30:209-212)

Key terms: osteoporosis; exercise; bone density; subjective back complaints

After menopause bone fractures, particularly of the distal radius, hips, and vertebral bodies, increase significantly in parallel with the amount of bone loss. ${ }^{1}$ Similarly, the prevalence of back pain and disability increases as a function of the severity of osteoporosis and subsequent vertebral deformities. ${ }^{2-4}$ These factors highlight the need for effective prevention of osteoporosis. A sedentary lifestyle promotes bone loss, muscular weakness, faulty posture, and chronic back pain. ${ }^{56}$ On the other hand, physical activity may prevent osteoporosis, back pain, ${ }^{6}$ and bone fractures. ${ }^{8}$ Yet long term studies testing the effects of therapeutic exercise on bone mass, fracture rate, and back complaints in postmenopausal women are scarce, methodologically flawed, and inconsistent in terms of outcome. The aim of the present study, therefore, was to evaluate the effectiveness of regular long term therapeutic exercises on bone density in untrained postmenopausal women.

\section{Methods}

All patients were recruited from the outpatient clinic of the department of physical medicine and rehabilitation, University of Vienna. Women were eligible for the study if they had given informed consent, were Caucasian, 45 to 75 years old, had moderate idiopathic mid or low back complaints without signs of nerve root compression for at least one year, had been postmenopausal for at least one year, did not suffer from any disease other than osteoporosis, were non-smokers and were not taking drugs affecting bone metabolism, and were reported to lead a sedentary lifestyle during the previous 10 years. Moderate back complaints were defined as back pain during brisk walking, standing, or sitting for more than one hour, lifting weights, bending down, carrying shopping bags, or other vigorous activities of daily living. The menopausal status was confirmed by testing for raised concentrations of follicle stimulating hormone $(>30 \mathrm{mU} / \mathrm{ml})$. All subjects also had to have normal values for complete blood cell count, urinalysis, serum glutamic oxaloacetic transaminase, alkaline phosphatase, bilirubin, electrolytes, total thyroxine, and parathyroid hormone.

All participants were randomly allocated (sealed envelope method) to a control group (group 3) or an exercise group. Women not showing up for follow up visits or women starting drug treatment for osteoporosis during the trial period were excluded from the study. According to the women's compliance with the exercise programme, the experimental group was retrospectively divided into two subgroups: one performed the exercise programme regularly at least three times per week, each session lasting 20 minutes or longer (group 1); the other (group 2) interrupted treatment or exercised irregularly (less than one hour a week).

TREATMENT

The major exercises performed are depicted in figs 1,2 , and 3 . The programme started with warm ups of moderate intensity (fig 1), stretching exercises (fig 2) (mainly affecting iliopsoas, gastrocnemius, lateral rotation, pectoralis muscles, hamstrings), and exercises directed towards improving faulty posture, motor control, coordination, and mechanical efficiency during daily living (fig 3). The latter group of exercises was designed according to 

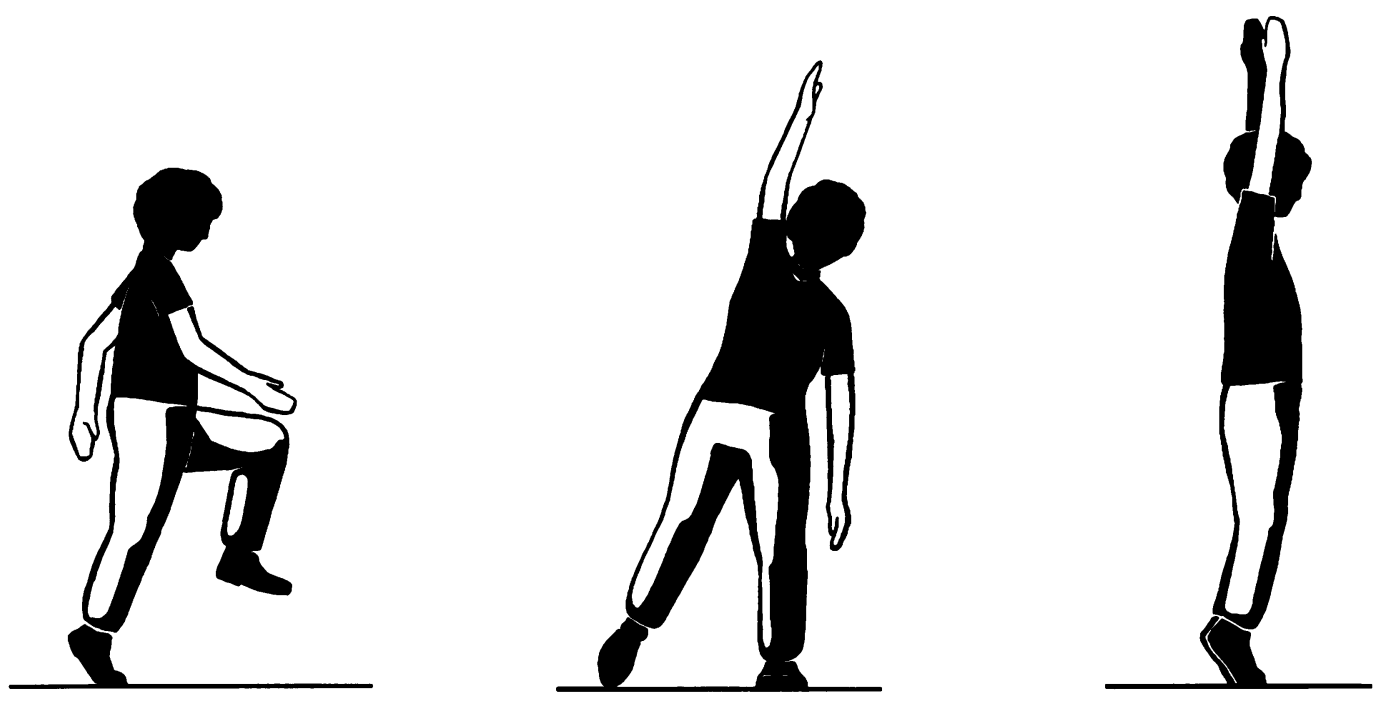

Figure 1 Moderate warm ups.

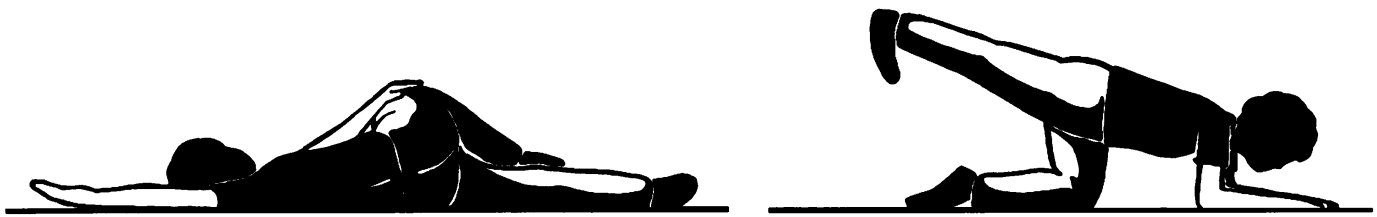

Figure 2 Stretching for improvement of flexibility.
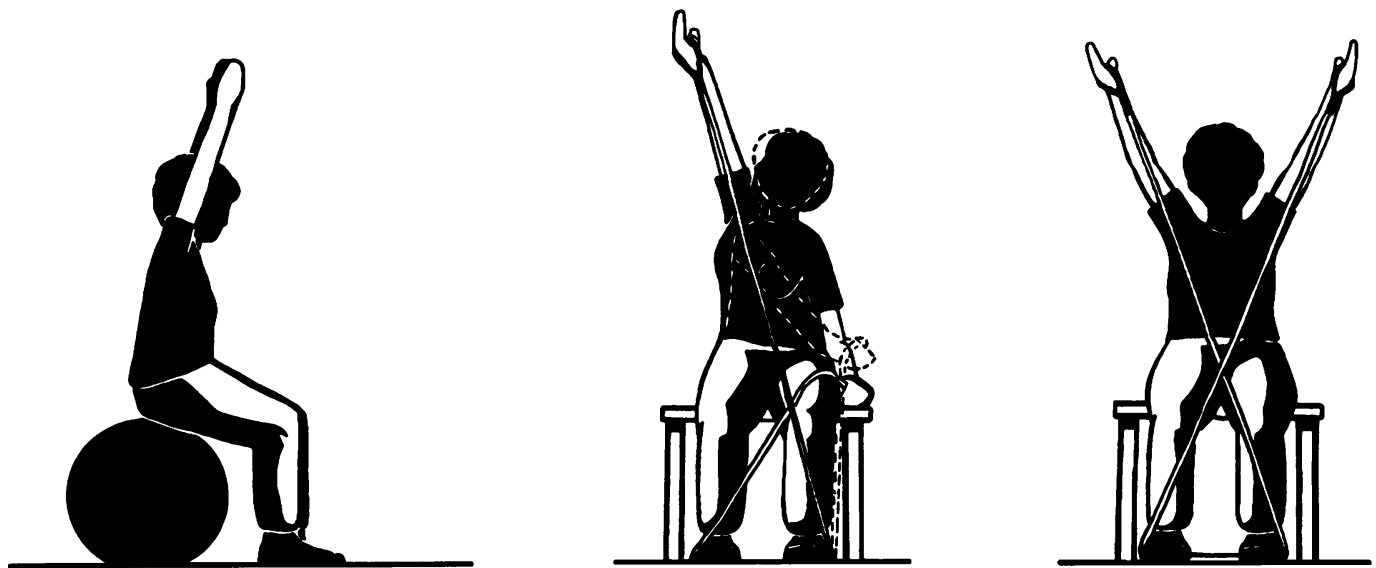

Figure 3 Improving of postural stability, motor control, coordination, and muscle strength.

Brunkow, ${ }^{9}$ Klein-Vogelbach, ${ }^{10}$ Brügger, ${ }^{11}$ and Knott. $^{12}$ For facilitating postural stability, motor control, and coordination, unstable equipment was used (big gymnastic balls and elastic bands). To train movement patterns adapted to functional activities, repetitive exercises were performed (three repetitions for each exercise), using exercises where muscle tension forces from the peripheral sites of the extremities were linked to achieve simultaneous contraction of trunk stabilising muscles.

During the initial 20 sessions, exercises were supervised by a physiotherapist. Thereafter patients were instructed to perform the exercises regularly three times a week and record this in a diary. Patients were invited to supervised sessions at least 10 times per year.

The control group did not receive any exercise therapy. Additional treatments for back pain consisted of local heat, massage, and electrotherapy. Whenever needed, these were offered to both the exercise and the control group for a maximum of 20 sessions. In addition all patients received dietary instructions motivating them to eat calcium-rich food. No patient took drugs affecting bone metabolism or anti-inflammatory drugs.

\section{ASSESSMENT AND FOLLOW UP}

At entry as well as after four years, osteoporotic vertebral deformities were diagnosed by three biplanar $x$ rays of the thoracic and lumbar spine. Bone densities of the non-dominant forearm were measured by single photon absorptiometry (Osteodensitometer Nuclear Data 1100 A TM; Schaumburg). Bone mineral content and bone width were estimated by calculating the mean of four distal (distal forearm) and six proximal (mid-forearm) scans distal to a radio-ulnar distance of $8 \mathrm{~mm}$. The bone mineral content/bone width ratio was calculated as an indicator of forearm bone mineral density (BMD, $\mathrm{g} \mathrm{cm}^{-2}$ ). 
Table 1 Baseline characteristics of both exercise groups and the control group

\begin{tabular}{llll}
\hline Characteristics & Group 1 (compliers) & $\begin{array}{l}\text { Group 2 } \\
\text { (non-compliers) }\end{array}$ & Group 3 (controls) \\
\hline Number of subjects & 27 & 34 & 31 \\
$\begin{array}{c}\text { Age, years; mean (SD) } \\
\text { Years since menopause; }\end{array}$ & $62.6(5.9)$ & $60.9(7.8)$ & $59.0(8.0)$ \\
$\quad 14.4(7.2)$ & $13.8(6.0)$ & $10.2(1.1)$ \\
$\begin{array}{c}\text { Forean (SD) } \\
\text { mg cm bone density, }\end{array}$ & & \\
$\quad \begin{array}{l}\text { Distal forearm } \\
\quad \text { Mid-forearm }\end{array}$ & $266(9.6)$ & $269(9.3)$ & $305(9.4)^{\star}$ \\
$\begin{array}{c}\text { Clinical manifestations } \\
\text { of osteoporosis (n) }\end{array}$ & 9 & $383(12.1)$ & $424(9.8)^{\star}$ \\
\hline
\end{tabular}

$\star \mathrm{P}<0.05$, group $1 v$ group 3.

In addition, physical activities during daily living, frequency and duration of exercise, intensity of back complaints, and the occurrence of bone fractures were recorded by standardised questionnaire. Changes in back complaints were rated by a three point numerical scale. All assessments were made by the same investigator, who was unaware of the results of BMD measurements. At entry and after the follow up period the calcium content of the diet was determined by scoring the consumption of calcium-rich food during a four day period.

\section{STATISTICAL ANALYSIS}

The paired $t$ test was used to analyse changes versus baseline longitudinally, after confirmation of normal distribution. For cross sectional comparisons, analysis of variance procedures (non-parametric: Kruskal-Wallis) were used. For nominally or ordinally scaled variables contingency table analyses ( $\chi^{2}$ test, Fisher's exact test) were performed. The null hypothesis was rejected when $P$ was less than 0.05 .

\begin{abstract}
Results
Only $44 \%$ of those subjects completing the study in the experimental group exercised at least three times a week for 20 minutes, thus qualifying for group 1 . The baseline data of the control group and both exercise groups are shown in table 1 . Twenty four women of both exercise subgroups and nine of the control group had clinical manifestations of osteoporosis, that is, osteoporotic vertebral deformities (one or more examples of wedging or compression fractures) or had previously suffered a peripheral fragility fracture. The baseline
\end{abstract}

Table 2 Changes in bone density, bone fractures, and back pain during the study period

\begin{tabular}{|c|c|c|c|}
\hline Index & Group 1 (compliers) & $\begin{array}{l}\text { Group } 2 \\
\text { (non-compliers) }\end{array}$ & Group 3 (controls) \\
\hline \multicolumn{4}{|l|}{$\begin{array}{l}\text { Change in forearm } \\
\text { bone density }, \mathrm{mg} \\
\mathrm{cm}^{-2}\end{array}$} \\
\hline $\begin{array}{l}\text { Distal forearm; } \\
\text { mean (SEM) }\end{array}$ & $3.7(5.5) \ddagger$ & $-20.8(4.7) \ddagger$ & $-19.6(6.5) \ddagger$ \\
\hline $\begin{array}{l}\text { Mid-forearm; } \\
\text { mean (SEM) }\end{array}$ & $-8.5(6.0)$ & $-24.0(4.7) \ddagger$ & $-27.6(5.4) \ddagger$ \\
\hline Vertebral fractures (n) & 1 & 0 & 3 \\
\hline Fragility fractures (n) & 5 & 3 & 2 \\
\hline $\begin{array}{l}\text { Improvement of back } \\
\text { pain }\end{array}$ & $19^{\star}$ & 15 & 13 \\
\hline
\end{tabular}

${ }^{2}$ Baseline value minus value at the end of study period.

$\star \mathrm{P}<0.05$, group $1 v$ group 3 .

$+\mathrm{P}<0.01$, group $1 v$ group 3 .

$\ddagger \mathrm{P}<0.01$, baseline $v$ final values.
BMD values at the two forearm sites were higher in controls (group 3) than in groups 2 or 1 .

The longitudinal changes within the three groups are summarised in table 2 . Bone loss was significant in groups 2 and 3 at either forearm site. No such change occurred in group 1 . The rate of $\mathrm{BMD}$ reduction at the distal forearm site was significantly less in group 1 than in group 2 or 3 . No significant intergroup differences in vertebral and non-vertebral fracture rates were noted. Back complaints decreased significantly in group 1 only. No significant longitudinal changes in calcium intake, physical activities (other than the prescribed exercises), height, and body weight were recorded (data not shown).

\section{Discussion}

These findings confirm previous reports implying that regular exercise can modify postmenopausal bone loss and ameliorate back problems.? In these studies treatment periods were relatively short and concomitant drug treatment could have confounded the results. Our trial was designed to overcome such methodological flaws.

Following four years of regular exercise, no significant change in BMD was found in group 1. However, the rate of decrease at the distal forearm was significantly more favourable when compared to unexercised controls (group 3) or to subjects who were not fully compliant (group 2). This implies that only continued regular mechanical strain will result in meaningful changes in bone mass, a notion which is also supported by previous findings. ${ }^{15}$ Of course, changes at one skeletal site do not necessarily reflect those at another, and BMD values may be different in the vertebra. Similarly changes in BMD may not reflect changes in bone strength.

Our study is limited by the fact that group 1 represents a self selected group of responders and by the high drop out rate in group 3 . Although forearm bone loss was apparently slowed by our exercise regimen, the incidence of bone fractures was not affected, but numbers were small and therefore interpretation is difficult. During the follow up period we recorded two wrist fractures and three new vertebral fractures in group 3, while four wrist fractures, one fracture of the proximal humerus, and one traumatic vertebral compression fracture occurred in group 1, and three wrist fractures were recorded in the exercise group 2 . With these relatively small numbers of events, statistical power regarding this variable is insufficient. Larger randomised trials will need to determine the efficacy of exercise in reducing fracture rates.

According to previous studies, ${ }^{16-19}$ loading exercises, that is, weight lifting, jumping, and running, appear to be best suited for improving bone mass. Such exercises are associated with a relatively high risk of injuries and are, for a variety of reasons, often not acceptable to elderly patients with osteoporosis. On the other hand, non-loading exercises with a low risk of 
injuries may be less effective in modifying bone mass. ${ }^{2021}$ Therefore, an exercise programme for frail patients should provide sufficient load without being hazardous or harmful. The exercise regimen chosen for this study was directed towards relieving back complaints by improving postural stability, mobility, motor control, and coordination during physical activities of daily living. The emphasis in training for coordination and control was on repetitive, moderate exercises predominantly in upright positions designed to train movement patterns and trunk extension. These were mainly low resistance dynamic exercises, involving all large muscle groups of the body (also at the site of BMD measurement). The present results imply that this type of programme may be a good compromise between sufficient loading and excess risk of injury.

Bone tissue is remodelled in response to activation of systemic hormonal factors and to local load bearing. ${ }^{22}{ }^{23}$ It has been postulated that strain-related electrical potentials within the bone mediate the adaptive response. ${ }^{2425}$ Bone cells may increase their production of prostaglandin $\mathrm{E}_{2}\left(\mathrm{PGE}_{2}\right)$ with increasing mechanical strain. ${ }^{26} \mathrm{PGE}_{2}$ may be important for osteoblast function: it mediates the resorptive response to cytokines and growth factors in bone. ${ }^{27}$ Therefore a positive effect on bone metabolism in response to intermittent mechanical force is conceivable and may explain how regular, moderate, dynamic loading exercises increase bone mass.

We conclude that a long term regular exercise programme designed to improve postural stability, mobility, motor control, coordination, and mechanical efficiency is effective in the prevention of osteoporosis. It improves back complaints and may delay bone loss. Its influence on fracture rate needs further investigation.

1 Consensus Development Conference. Diagnosis, prophylaxis, and treatment of osteoporosis. $\mathrm{Am} \mathcal{F} \mathrm{Med}$ laxis, and treat

2 Ettinger B, Black DM, Nevitt MC, Rundle AC, Cauley JA, to chronic back pain and disability. $\not$ F Bone Miner Res 1992 ; to chronic

3 Ross PD, Ettinger B, Davis JW, Melton LJ, Wanich RD.
Evaluation of adverse health outcomes associated with vertebral fractures. Osteoporosis Int 1991;1:134-40.

4 tebral fractures. Osteoporosis Int 1991;1:134-40. Silverman SL. The clinical consequences

5 Arnaud SB, Schneider VS, Morrey-Holton E. Effects of inactivity on bone and calcium metabolism. In: Sandler $\mathrm{H}$, Vernikos H, eds. Inactivity; physical effects. Orlando: Academic Press, 1986:49-76.

6 Ernst E, Fialka V. Physical stress in low back pain. Eur $\mathcal{F}$ Phys Med Rehab 1994;3:76-8

Ernst E. Can exercise prevent postmenopausal osteoporosis? Br $\mathcal{F}$ Sports Med. 1994;28:5-6.

8 Nguyen T, Sambrook P, Kelly P, Jones G, Lord S, Freund J, et al. Prediction of osteoporotic fractures by postural instability and bone density. BMF 1993;307:1111-5.

9 Bold RM, Grossmann A. Stemmführung nach Brunkow. Stuttgard: Enke, 1987

10 Klein-Vogelbach S. Ballgymnastik zur funktionellen Bewegungslehre, 3rd ed. Berlin: Springer Verlag, 1990.

11 Brügger A. Gesunde Körperhaltung im Alltag, 3rd ed. Zurich: Brügger, 1990

12 Knott M, Voss DE. Proprioceptive neuromuscular facilitation, patterns and techniques, 2nd ed. New York: Harper and Row, 1968.

13 Manniche C, Hesselsøe G, Bentzen L, Christensen I, Lundberg $E$. Clinical trial of intensive muscle training for chronic low back pain. Lancet 1988;ii:1473-6.

14 Elnaggar IM, Nordin M, Scheikhzadeh A, Parnianpour M, Kahanovitz N. Effects of spinal flexion and extension exercises on low-back pain and spinal mobility in chronic mechanical low-back pain patients. Spine 1991;16:967-2.

15 Dalsky GP, Stocke KS, Ehsani AA, Slatopolsky E, Lee WC, Birge SJ. Weight-bearing exercise training and lumbar bone mineral content in postmenopausal women. Ann Intern Med 1988;108:824-8.

16 Aloia JF, Cohn SH, Babu T, Abesamis C, Kalici N, Ellis K Skeletal mass and body composition in marathon runners. Metabolism 1978;27:1793-6.

17 Heinrich CH, Going SB, Pamenter RW, Perry CD, Boyden TW, Lohman TG. Bone mineral content of cyclically menstruating female resistance and endurance trained athletes. Med Sci Sports Exerc 1990;22:558-63.

18 Margulies JY, Simkin S, Leichter I, Bivas A, Steinberg R Giladi $M$, et al. Effect of intense physical activity on the bonemineral content in the lower limbs of young adults. $\mathcal{F}$ Bone foint Surg? 1986;68A:1090-3.

19 Risser BL, Lee EJ, Leblanc A, Pointdexter HBW, Risser JMH, Schneider V. Bone density in eumenorrheic female college athletes. Med Sci Sports Exerc 1990;22:570-4.

20 Orwoll ES, Ferar J, Oviatt SK, McClung MR, Huntington $\mathrm{K}$. The relationship of swimming exercise to bone mass in
men and women. Arch Intern Med 1989;149:2197-200.

21 Sinaki M, Wahner HW, Offort KP, Hodgson SF. Efficacy of nonloading exercises in prevention of vertebral bone loss in nonloading exercises in prevention of vertebral bone loss in postmenopausal

22 Frost HM. The mechanostat: a proposed pathogenic mechanism of osteoporosis and the bone mass effects of mechanical and nonmechanical agents. Bone Miner 1987;2 73-85.

23 Lanyon LE. Functional strain as a determinant for bone remodelling. Calcif Tiss 1984;36:S56-61.

24 Fukada E, Yasuda. On the piezoelectric effect on bone. $\mathcal{J}$ Phys Soc Jpn 1957;12:1158-62

25 Basset CA, Becker RO. Generation of electric potentials by bone in response to mechanical stress. Science 1962;137: 1063-4.

26 Raisz LG, Pilbeam CC, Klein-Nuled J, Harrison JR Prostaglandins and bone metabolism: possible role in osteoporosis. Osteopress 1990:253-8.

27 Canalis E, McCarthy TL, Centrella M. Production, regulation and effects of bone growth factors. Osteoporosis 1990. Osteopress 1990:243-7. 